\title{
EFFECT OF AGGREGATES IMPURITY ON CONCRETE PROPERTIES
}

\begin{abstract}
Rytis SKOMINAS, Institute of Hydraulic Engineering, Vytautas Magnus University, Universiteto 10, LT-53361, Akademija, Kaunas dist., Lithuania, rytis.skominas@ vdu.lt (corresponding author)

Vincas GURSKIS, Institute of Hydraulic Engineering, Vytautas Magnus, Universiteto 10, LT-53361, Akademija, Kaunas dist., Lithuania, vincas.gurskis@ vdu.lt

Raimondas ŠADZEVIČIUS, Institute of Hydraulic Engineering, Vytautas Magnus University, Universiteto str. 10, LT-53361 Akademija, Kaunas distr., Lithuania, raimondas.sadzevicius@vdu.lt

Dainius RAMUKEVIČIUS, Researcher; Institute of Hydraulic Engineering, Vytautas Magnus University, Universiteto 10, LT-53361, Akademija, Kaunas dist., Lithuania, dainius.ramukevicius@ vdu.lt

Concrete is one of the most popular construction materials in the world. The concrete properties depend from many factors. One of them is aggregates quality, which can be defined as an impurity level. The most unwanted materials in fine aggregates are clay and soil particles. These particles can impure aggregates due to irregular sands in quarry and during the digging process. In the present paper were estimated how impurity impact the properties of concrete. During the research the aggregates were impured with clay and soil particles. The change of fresh concrete workability, hardened concrete density, compression strength, water absorbability and frost resistance were evaluated. The results show that aggregates impurity with clay and especially with organic materials (soil) is very dangerous. The concrete workability, frost resistance is decreasing. The clay and soil have a different effect on hardened concrete density and compression strength. Soil decreased both parameters while well mixed clay increased these characteristics. However, generalizing all results, can be stated, that keeping the same level of concrete workability it is necessary to raise water and cement ratio and it will give strength loss effect.
\end{abstract}

Keywords: concrete, aggregates, impurity, workability, compression strength, water absorbability, frost resistance.

\section{INTRODUCTION}

More than 50 years one of the most popular construction materials is concrete. The concrete properties depend from many factors, like: water and cement ratio, cement characteristics, aggregates type and aggregates quality. The aggregates quality mostly depends from the impurity. The impurity can cause the worse binding process, decrease the density, strength and start corrosion. The concrete aggregates can be impured with different materials such as clay, dust, organic materials, salts, gypsum, anhydrite and reactive rocks. The coarse aggregates mainly are impurd with dust particles and reactive rocks as well as the fine aggregates are impured with clay, dust and organic particles. There are more possibilities that fine aggregates will have higher impurity due to smaller fractions.

Generally the fine aggregates are digging from quarries where the quality of production is controlled (aggregates must be tested in laboratories at the certain frequency). Unfortunately, there is possibility that sand will have different properties and impurity in different quarry places and aggregates with not suitable quality will reach concrete production unit.

Recently there are made few research works in this field (Nehdi, 2014). Olanitori (2006) reported that the higher clay and silt content in sand, the higher was the cement dosage increment needed to maintain the compressive strength of concrete beyond $20 \mathrm{MPa}$. Li et al. (2012) studied the workability, strength and modulus of elasticity, drying shrinkage and creep, freeze-thaw resistance of C60/75 high-performance concrete made with manufactured sand containing 3.5-14\% crushed limestone dust, versus that made with river sand with clay amounts of $3 \%$ and $5 \%$. The clay content in manufactured sand decreased workability, increased drying shrinkage and accelerated freeze-thaw damage, but did not affect its compressive strength. Norvell et al. (2007) in their research found out that at constant w/c, smectite (montmorillonite) clay decreased compressive strength and increased drying shrinkage. Fernandes et al. (2006) carried out an experimental study on claycement-sand composites. They concluded that the effect of clay is significant and structural concrete made with such materials needs proper durability and dimensional stability investigation.

The scientific works presents the clay impact on concrete properties, however it is missing more detailed data about it and how organic materials impacts concrete properties.

The aim of the research is to estimate how impurity of aggregates with clay and soil particles impacts the properties of concrete.

Copyright () 2019 The Authors. Published by Vytautas Magnus University. This is an open-access article distributed under the terms of the Creative Commons Attribution License (CC BY 4.0), which permits unrestricted use, distribution, and reproduction in any medium, provided the original author and source are credited. 


\section{MATERIALS}

During the research the concrete was impured with clay and with organic materials (soil). For impuring concrete with clay was used different amount (from 3 to $6 \%$ ) of clay powder $(<0.0063 \mathrm{~mm}$ ). To estimate the effect of soil to concrete properties was used natural soil (fraction $0 \ldots 2 \mathrm{~mm}$ ). The amount of soil was from 3 to $6 \%$.

Concrete was prepared using cement CEM II/A-L 42,5 N, coarse aggregate - crushed granite (fraction $4 \ldots 16 \mathrm{~mm}$ ) and fine aggregate - sand (fraction $0 \ldots 4 \mathrm{~mm}$ ), the water-cement ratio $\mathrm{W} / \mathrm{C}=0.5$. Aggregates and water meet the requirements described in European standards EN 12620:2002+A1:2008 and EN 1008:2002. To get more workable concrete was used plasticizer Vinmix.

The class of control concrete (with natural impurity $-2 \%$ ) was selected $-\mathrm{C} 16 / 20$, in purpose, correctly to estimate the impact of impurity with clay and soil particles on concrete properties.

\section{TEST METHODS}

The consistency of fresh concrete was estimated according to standard methods (EN 12350-2:2009 and EN 123505:2009). The compression strength, and water absorbability of hardened concrete were established according to standard

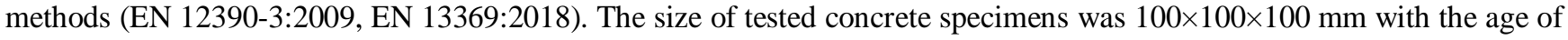
28 days. Test of fresh and hardened concrete were applied to control concrete and concrete with impured aggregates. The impurity amount was selected 3, 4, 5 and $6 \%$ (the natural impurity of aggregates (2\%) is not included).

The impact of impurity on frost resistance was estimated too. Frost resistance was calculated using methodology presented in (Vaisvila et al., 2004).

\section{TEST RESULTS}

Mixing the concrete with different impurity with clay and soil particles firstly mixture was tested for consistency. To estimate this property was used two methods: cone slump test and Vebe test. The results are presented in Table 1. According to results it is possible to conclude that impurity with both materials (clay and soil) has a negative effect on concrete consistency. The control concrete mixture with natural impurity (2\%) suited S3 slump class (high workability). Increasing impurity turned concrete mixture with clay suiting to V1 Vebe class and with soil to V2 Vebe class. Both these Vebe classes are described as low workability concrete. In this consistency concrete is not suitable for reinforced concrete structures. In this case to make more workable concrete it is necessary to use more water, unfortunately, it will have a negative effect on other concrete properties due to changed water and cement ratio.

Table 1. Concrete mixture consistency results

\begin{tabular}{|c|c|c|c|c|c|c|}
\hline $\begin{array}{c}\text { Concrete } \\
\text { mixture No }\end{array}$ & $\begin{array}{l}\text { Impurity with } \\
\text { clay, \% }\end{array}$ & $\begin{array}{l}\text { Impurity with } \\
\text { soil, \% }\end{array}$ & $\begin{array}{c}\text { Total } \\
\text { impurity, } \%\end{array}$ & Slump, mm & Vebe index, s & $\begin{array}{c}\text { Consistency } \\
\text { class }\end{array}$ \\
\hline 1 & - & - & 2 & 130 & & S3 \\
\hline 2 & 3 & - & 5 & 40 & & S1 \\
\hline 3 & 4 & - & 6 & 20 & & S1 \\
\hline 4 & 5 & - & 7 & & 7 & V3 \\
\hline 5 & 6 & - & 8 & & 22 & V1 \\
\hline 6 & - & 3 & 5 & 60 & & $\mathrm{~S} 2$ \\
\hline 7 & - & 4 & 6 & 20 & & S1 \\
\hline 8 & - & 5 & 7 & & 5 & V3 \\
\hline 9 & - & 6 & 8 & & 13 & V2 \\
\hline
\end{tabular}

The test results (Fig. 1) of hardened concrete density show difference depending on the type of impurity material. The density of concrete with increasing impurity with clay particles was increasing too (with the maximum impurity it increased approx. by $2 \%$ ) and the density of concrete with organic impurity has an opposite impact. In total (with the maximum impurity) the density in this case decreased approx. by $5 \%$. This phenomenon can be explained that clay weight is higher than soil and clay particles during the mixing better binds with other concrete components. 


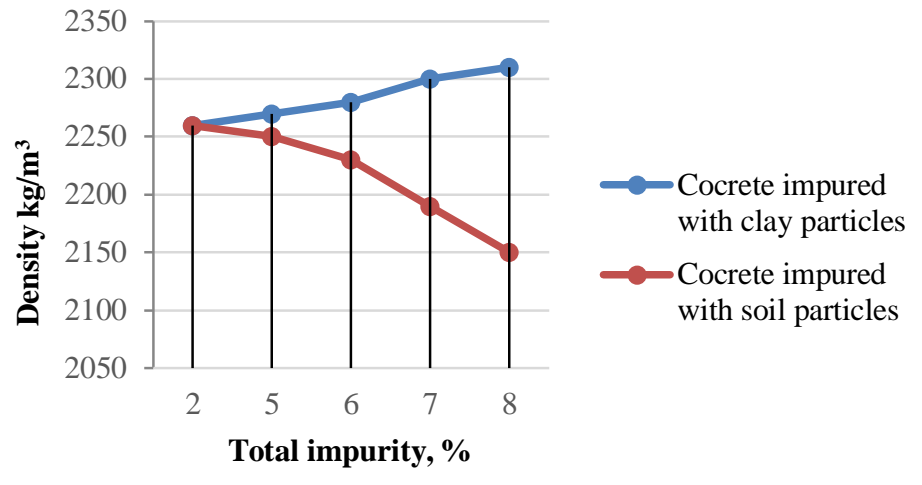

Figure 1. Aggregates impurity impact on hardened concrete density

To estimate the main characteristic of concrete the compression test was performed. Summarizing compression strength test results (Table 2, Fig. 2) can be concluded that increasing impurity with clay particles in concrete have a positive effect on this property. For example, with $5 \%$ total impurity the strength will grow approx. by $8 \%$ and with $8 \%$ total impurity the strength will grow approx. by $33 \%$ (the concrete class will increase from C16/20 to C25/30). The opposite results show impured concrete with organic materials. For example, with $8 \%$ total impurity the strength loss will be approx. by $58 \%$ (the concrete class will decrease from $\mathrm{C} 16 / 20$ to $\mathrm{C} 8 / 10)$.

Table 2. Compression strength test results

\begin{tabular}{|c|c|c|c|c|c|c|}
\hline $\begin{array}{c}\text { Concrete } \\
\text { mixture No }\end{array}$ & $\begin{array}{c}\text { Impurity with } \\
\text { clay, \% }\end{array}$ & $\begin{array}{c}\text { Impurity with } \\
\text { soil, \% }\end{array}$ & $\begin{array}{c}\text { Total } \\
\text { impurity, \% }\end{array}$ & $\begin{array}{c}\text { Compression } \\
\text { strength }\end{array}$ & $\begin{array}{c}\text { Compression } \\
\text { strength class }\end{array}$ & $\begin{array}{c}\text { Strength grow } \\
+/ \text { loss-, } \%\end{array}$ \\
\hline $\mathbf{1}$ & - & - & 2 & 24.69 & $\mathrm{C} 16 / 20$ & - \\
\hline $\mathbf{2}$ & 3 & - & 5 & 26.78 & $\mathrm{C} 16 / 20$ & +7.8 \\
\hline $\mathbf{3}$ & 4 & - & 6 & 28.73 & $\mathrm{C} 16 / 20$ & +14.1 \\
\hline $\mathbf{4}$ & 5 & - & 7 & 30.88 & $\mathrm{C} 20 / 25$ & +20.0 \\
\hline $\mathbf{5}$ & 6 & - & 8 & 36.78 & $\mathrm{C} 25 / 30$ & +32.9 \\
\hline $\mathbf{6}$ & - & 3 & 5 & 24.32 & $\mathrm{C} 16 / 20$ & -1.5 \\
\hline $\mathbf{7}$ & - & 4 & 6 & 23.15 & $\mathrm{C} 12 / 15$ & -6.7 \\
\hline $\mathbf{8}$ & - & 5 & 7 & 19.50 & $\mathrm{C} 12 / 15$ & -26.6 \\
\hline
\end{tabular}

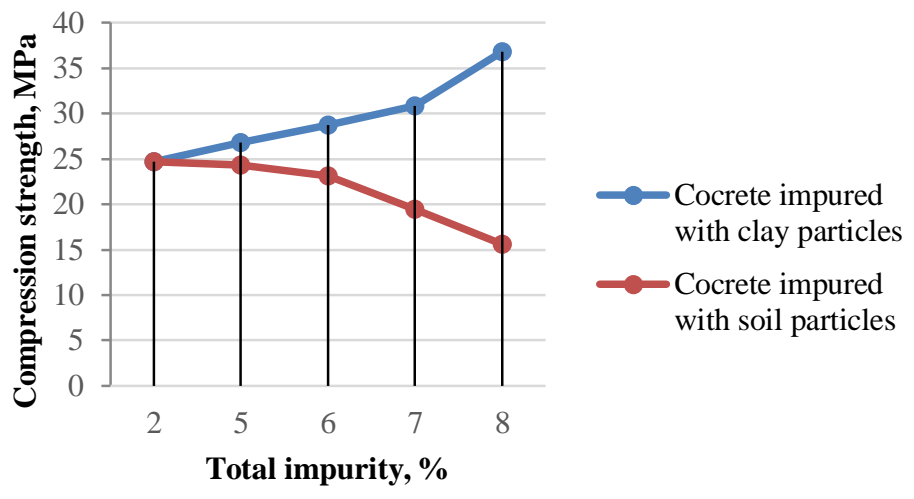

Figure 2. Aggregates impurity impact on concrete strength

The test results with clay impurity confirm the Parsons research results (Parsons, 1933). However, these results show only compression strength of low workable concrete. If it is necessary to have the same consistency as control concrete, it will be necessary to change a composition adding more water. In this case it will be lost the strength.

The concrete impurity with clay and soil particles has a negative effect on water absorbability (Fig. 3). The increasing amount of clay and soil particles in concrete increases the water absorbability from 4.5 to $7.4 \%$. The higher water absorbability than $7 \%$ is dangerous for outside structures which have a contact with water during the winter time. Therefore, in this case, the concrete with $8 \%$ of total impurity is not suitable for these type of structures. 


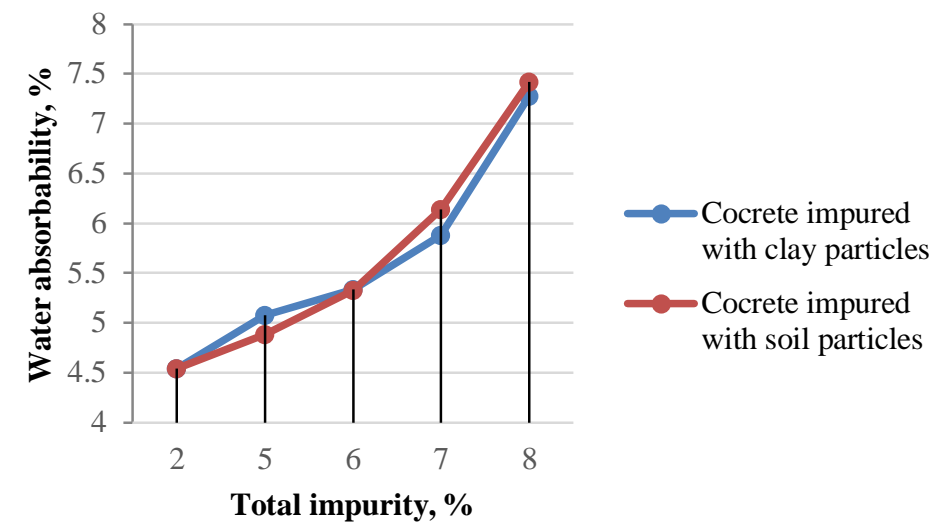

Figure 3. Aggregates impurity impact on concrete water absorbability

Using the methodology presented in (Vaisvila et al., 2004) the frost resistance was calculated. This methodology includes three concrete properties which were estimated in laboratory: hardened concrete density, water absorbability and compression strength. The calculation results are presented in Table 3. The results show that increasing impurity with clay and soil particles have a negative effect on frost resistance. For example, with $8 \%$ total impurity with clay particles, the frost resistance mark will decrease from F150 to F75 and with $8 \%$ total impurity with soil particles, the frost resistance mark will decrease from F150 to F50.

Table 3. Frost resistance calculation results

\begin{tabular}{|c|c|c|c|c|c|}
\hline Concrete mixture No & $\begin{array}{c}\text { Impurity with } \\
\text { clay, \% }\end{array}$ & $\begin{array}{c}\text { Impurity with } \\
\text { soil, \% }\end{array}$ & Total impurity, \% & Frost resistance cycles & Frost resistance mark \\
\hline $\mathbf{1}$ & - & - & 2 & 169 & F150 \\
\hline $\mathbf{2}$ & 3 & - & 5 & 134 & F125 \\
\hline $\mathbf{3}$ & 4 & - & 6 & 125 & F125 \\
\hline $\mathbf{4}$ & 5 & - & 7 & 112 & F100 \\
\hline $\mathbf{5}$ & 6 & - & 8 & 138 & F75 \\
\hline $\mathbf{6}$ & - & 3 & 5 & 121 & F125 \\
\hline $\mathbf{7}$ & - & 4 & 6 & 89 & F100 \\
\hline $\mathbf{8}$ & - & 5 & 7 & 63 & F75 \\
\hline
\end{tabular}

Generalizing all results can be stated that aggregates impurity with clay and especially with organic materials (soil) is very dangerous. The concrete workability, frost resistance is decreasing. The clay and soil have a different effect on hardened concrete density and compression strength. Soil decreased both parameters while well mixed clay increased these characteristics. Unfortunately, it is not possible to state as a positive effect due to decreased workability. To have a proper workability it is necessary to change concrete composition adding more water. This will give a density and strength loss.

\section{CONCLUSIONS}

1. The increasing impurity of aggregates have a negative effect on fresh concrete workability. The $8 \%$ impurity with clay or soil particles changed concrete mixture from high workable to low workable.

2. The well mixed clay in fresh concrete increased the density and strength. The concrete with $8 \%$ impurity with clay changed the class from $\mathrm{C} 16 / 20$ to $\mathrm{C} 25 / 30$. The opposite results have concrete which aggregates were with soil particles. Here the concrete class changed from $\mathrm{C} 16 / 20$ to $\mathrm{C} 8 / 10$.

3. The impurity with clay and soil have a negative effect on concrete water absorbability and frost resistance. The increasing impurity significantly worsens these properties.

\section{REFERENCES}

1. EN 1008:2002 Mixing water for concrete - Specification for sampling, testing and assessing the suitability of water, including water recovered from processes in the concrete industry, as mixing water for concrete.

2. EN 12350-2:2009 Testing fresh concrete - Part 2: Slump-test.

3. EN 12350-5:2009 Testing fresh concrete - Part 5: Flow table test. 
4. EN 12390-3:2009 Testing hardened concrete - Part 3: Compressive strength of test specimens.

5. EN 12620:2002+A1:2008 Aggregates for concrete.

6. EN 13369:2018 Common rules for precast concrete products.

7. Fernandes V. A., Purnell P., Still G. T., Thomas T. H. 2007. The effect of clay content in sands used for cementitious materials in developing countries. Cement and Concrete Research, Vol. 37, pp. 751-758. https://doi.org/10.1016/j.cemconres.2006.10.016

8. Li B. X., Wang J. I., Zhou M. K. 2009. C60 high performance concrete prepared from manufactured sand with a high content of microfines. Key Engineering Materials, Vol. 405-406. https://doi.org/10.4028/www.scientific.net/KEM.405-406.204

9. Nehdi M. L. 2014. Clay in cement-based materials: Critical overview of state-of-the-art. Construction and Building Materials, Vol. 51, pp. 372-382. https://doi.org/10.1016/j.conbuildmat.2013.10.059

10. Norvell J. K, Stewart J. G., Juenger M. C. G., Fowler D. W. 2007. Influence of clays and claysized particles on concrete performance. Journal of Materials in Civil Engineering, Vol. 19(12), pp. 1053-1059. https://doi.org/10.1061/(ASCE)0899-1561(2007)19:12(1053)

11. Olanitori L. M. 2006. Mitigating the effect of clay content of sand on concrete strength. 31st Conference on our world in concrete \& structures.

12. Parsons D. A. 1933. Clay in concrete. Journal of Research of the National Bureau of Standards, Vol. 10, pp. $267-73$. https://doi.org/10.6028/jres.010.020

13. Vaisvila K. A., Ramonas C., Mikuckis F., Gurskis V. 2004. Strength of Hydraulic Structures Concrete Affected by Freezing Cycles. Vagos, Vol. 63 (16), pp. 102-111. 